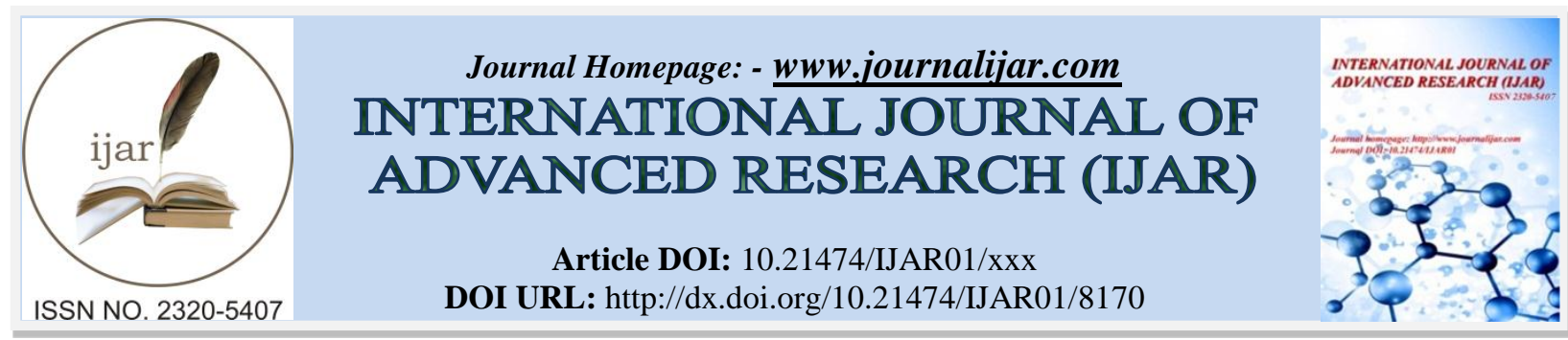

RESEARCH ARTICLE

\title{
DIAGNOSIS OF CHRONIC RENAL INSUFFICIENCY BY COCKCROFT FORMULA IN ELDERLY ADULTS WITH DIABETES MELLITUS TYPE II.
}

\author{
Betty Sarabia Alcocer ${ }^{1}$, Luis Alberto Núñez Oreza ${ }^{2}$, Ana Rosa Can Valle ${ }^{3}$, Betty Mónica Velázquez Sarabia ${ }^{4}$, \\ Priscilla Karmina Velázquez Sarabia ${ }^{5}$, Julio Antonio Gutiérrez González ${ }^{6}$, Lidia María Maas Ortegón ${ }^{7}$, \\ Paulino Tamay Segovia ${ }^{2}$, Selene Blum Domínguez ${ }^{2}$, Patricia Margarita Garma Quen ${ }^{8}$, Rafael Manuel de \\ Jesús Mex Álvarez ${ }^{8}$ and Ángel Arturo Ake Ordoñez'. \\ 1. Professor and researcher at the Faculty of Medicine of the Autonomous University of Campeche. \\ 2. Center for Biomedical Research. Autonomous University of Campeche. \\ 3. Professor and researcher at the Faculty of Nursing of the Autonomous University of Campeche. \\ 4. Doctor Surgeon graduated from the Faculty of Medicine of the U.A.C. \\ 5. Law graduate and researcher. \\ 6. Professor and researcher of the engineering Faculty of the Autonomous University of Campeche. \\ 7. Professor and researcher of the Faculty of Law of the Autonomous University of Campeche. \\ 8. Professor and researcher at the Faculty of Biochemistry of the U.A.C. \\ 9. Student of the Licentiate Medical Surgeon.
}

\section{Manuscript Info}

\section{Manuscript History}

Received: 08 October 2018

Final Accepted: 10 November 2018

Published: December 2018

\section{Keywords:}

Black triangles, Interdental papilla reconstruction, connective tissue graft.

\section{Abstract}

Objective: To determine the diagnosis of Chronic Renal Insufficiency, by Cockcroft formula, in type II diabetic patients aged 40 to 80 years old from the community of Santa Cruz, Hecelchakán during the period from August 20017 to July 20018.

Materials and methods: This is a prospective, cross-sectional, descriptive and observational study in which the diagnosis of renal failure in any of its 5 stages will be investigated. Patients were asked for laboratory tests of plasma creatinine, weight and age, to later calculate the creatinine clearance using the Cockcroft and Gault formula and classify the stage of renal failure in which each patient is to formulate plans of practice of according to your state.

Results:We found 10 cases with chronic kidney disease in stage 1, 3 men and 7 women, in stage 28 patients were found, 2 men and 6 women, and 5 patients with stage 3 , all of them female.

Conclusions: In the community of Santa Cruz, Hecelchakán, there is a prevalence of $3.9 \%$ in diabetes mellitus, 42 people who come monthly from a total population of 1,060 according to the November 2017 population census.

Copy Right, IJAR, 2018,. All rights reserved.

\section{Introduction:-}

Type II Diabetes Mellitus (Type II DM) is one of the main causes of Chronic Renal Failure in our country. Sustained hyperglycemia, as well as poor metabolic control, lead to a progressive and declining condition of renal function. The improvement in the control of blood glucose and the most effective therapeutic measures to correct

Corresponding Author:-Betty Sarabia Alcocer ${ }^{1}$.

Address:-Professor and researcher at the Faculty of Medicine of the Autonomous University of Campeche. 
hypertension, which frequently accompanies this metabolic disorder, can reduce the development of end-stage renal disease among diabetics.

Chronic kidney disease (SRI) has acquired the proportions of a true epidemic, whose full spectrum is just beginning to be understood. Considering the demographic trend, it has been projected that, in the year 2030, there will be approximately 2.2 million patients that will require dialysis or transplantation.

Among the causes that lead to chronic renal failure, Type II Diabetes Mellitus occupies the first place accounting for $40 \%$ of patients who enter renal replacement therapy.

In the community of Santa Cruz, Hecelchakán, diabetic patients are people of low resources and low level of education, some still attached to traditional medicine to heal their illnesses; all these factors lead to poor compliance with the pharmacological and dietary measures implemented, which leads to a constant rise in blood glucose levels.

Chronic Renal Insufficiency (CRF) is defined as the progressive, permanent and irreversible loss of the Glomerular Filtration Rate (GFR) over a variable time, sometimes even years, expressed by a reduction in estimated creatinine clearance $<60 \mathrm{ml} / \mathrm{min} / 1.73 \mathrm{~m} 2^{(1)}$

Strictly speaking, any decrease in GFR below normal could be considered as renal failure, but for practical purposes renal failure is defined as a GFR $<60 \mathrm{ml} / \mathrm{min} / 1.73 \mathrm{~m} 2$, corresponding to phases 3,4 and 5 . (2).

It has been estimated that at least $6 \%$ of the adult population of the United States has chronic kidney injury with a GFR $>60 \mathrm{ml} / \mathrm{min}$ for $1.73 \mathrm{~m} 2$ of SC (stages 1 and 2), and therefore is at imminent risk of experiencing further deterioration progressive of this function. In addition, about $4.5 \%$ of the population of that country suffer from chronic kidney disease in stages 3 and 4 . $^{(3)}$

Diabetic nephropathy is the first cause of terminal stage nephropathy in the United States, and one of the leading causes of morbidity and mortality related to DM. (3) Patients with Diabetes Mellitus type 1 develop diabetic nephropathy in $30-40 \%$ of cases, while in patients with type II DM this percentage is reduced to $10-20 \%$. Although renal disease is less frequent in patients with type II DM, these are usually detected within the first 10 years following the clinical diagnosis. According to results of other investigations, the male sex is more predisposed to develop microalbuminuria. Another study mentions that it is likely that between $20-40 \%$ of patients with type II DM will progress to diabetic nephropathy in a period of approximately 10 years. ${ }^{(4)}$

Nephronal loss, regardless of its etiology, causes adaptive responses in the remaining nephrons that lead to hypertension and glomerular hyperfiltration, passage of proteins to the urinary space with proteinuria, intrarenal activation of the renin angiotensin system (RAS), tubular activation with tubulointerstitial involvement, transdifferentiation of tubular epithelial cells to myofibroblasts and finally fibrosis of the renal parenchyma with definitive loss of function ${ }^{(5)}$. The pathogenesis of diabetic nephropathy is related to chronic hyperglycemia.

CRF is a progressive disease that evolves in different stages in which clinical manifestations are increasing. These stages are established based on renal function measured by the estimated glomerular filtration rate. ${ }^{(2)}$

Stages of CRI: an action plan with a clinical approach

\begin{tabular}{|c|l|l|l|}
\hline Stage & \multicolumn{1}{|c|}{ Description } & \multicolumn{1}{|c|}{ Aftion } \\
\hline 1 & Kidney injury with normal or increased VFG & $\geq 90$ & $\begin{array}{l}\text { Dx and Tx Tx of concomitant } \\
\text { pathologies. Reduction of risk of } \\
\text { cardiovascular disease. }\end{array}$ \\
\hline 2 & Kidney injury with mild decrease in VFG & $60-89$ & Progression estimation \\
\hline 3 & Moderate decrease in VFG & $30-59$ & Complication evaluation and tx \\
\hline 4 & Severely decreased VFG & $15-29$ & $\begin{array}{l}\text { Preparation for renal function } \\
\text { substitution tx }\end{array}$ \\
\hline 5 & Renal insufficiency & $\begin{array}{l}<15 \text { o en } \\
\text { diálisis }\end{array}$ & Replacement \\
\hline
\end{tabular}

It is advisable to measure the GFR, either with the formula of the clearance or the estimated according to the formulas of Cockroft-Gault or MDRD. 


\section{Cockcroft and Gault formula}

VFG: $(140-$ age $) \mathrm{x}$ weight $(\mathrm{kg})$

PCr x 72

For women, the estimated VFG is multiplied by 0.85 because the muscle mass is smaller.

\section{Material And Methods:-}

A prospective, cross-sectional, descriptive and observational study was conducted within the period from August 2017 to July 2018, Rural Medical Unit of Santa Cruz, Hecelchakán. All patients between 40 and 80 years of age with type II DM who attended their monthly control at the UMR Santa Cruz were included, excluding all those who did not meet the previously established criteria.

The data collection was carried out through the review of clinical files, based on the ethical principles of the Declaration of Helsinki 1975 and the Mexican sanitary code; In the same way, the data collection questionnaire, formulated by the researcher, was applied to all diabetic patients in control. Among the data that were investigated are: age, gender, marital status, level of education, time of evolution of diabetes mellitus, serum creatinine, body weight and creatinine clearance by the Cockcroft and Gault formula. The results were analyzed and expressed by tables and graphs.

\section{Results:-}

The study was carried out in the Santa Cruz Rural Medical Unit, Hecelchakán, during the period from August 2017 to July 2018. The community of Santa Cruz is made up of a population of 1,060 inhabitants, of which, within the age group of 40 to 80 years comprise 239 people, distributed by sex in 121 men and 118 women, according to the November 2017 population census.

The percentage of type II DM in the studied age group is $17.57 \%$; that is, out of a total of 239 people, 42 have DM2. A total of 23 patients were included in the study, who met the inclusion criteria, 5 men and 18 women.

A total of 5 patients with CRF were found (defined as stages 3, 4 and 5). That is, in 21.73\% CRF was developed within the group of diabetic patients studied. The rest of the patients were in stages 1 and 2 , with 10 patients in stage 1, representing $43.47 \%$ and 8 patients in stage 2 with $34.78 \%$. (graph No. 1 ).

In Figure 2, we can see that we find 9 patients who have a time of evolution of type II DM that goes from 1 to 5 years, 39.13\%; in the range of 6-10 years of evolution were 9 patients, $39.13 \%$; 3 patients with a duration of type II DM of 11-15 years, 13.04 and only 2 with an evolution of 16 years and more, being $8.69 \%$. Among the 5 patients who presented renal failure, 1 was a diabetic with 1-5 years of evolution of type II DM, 20\%; 3 patients with an evolution of 6-10 years, being 60\% and 1 person with 16 and more years of DM2, with $20 \%$.

Regarding the predominance by age, in Table No. 1 we can find that 4 cases of CRI were found (stages 3, 4 and 5) in the age group of 60-69, with $80 \%$ and only 1 case in the group of 70-80 years, $20 \%$. The rest of the cases (which are not considered CRF because they correspond to stages (1 and 2) were distributed as follows: 9 patients in the age range of 40-49, 6 patients aged 50-59 years, 2 patients in the group of 60-69 and 1 patient without CKD in the group of 70-80 years (Graph No. 3).

In the distribution of cases of chronic renal failure according to the gender of the patients. We observed that no case of CRI was developed in the male sex; while 5 cases were detected in the female sex. (Graph No. 4)

The marital status of the patients, we obtained 0 singles, 18 married, which corresponds to $78.26 \%$; 4 widowed patients, $17.39 \%$; no patient divorced and 1 in free union, 4.34\%. (Graph No. 5)

The division of diabetic patients according to their level of education. We found a total of 21 illiterate patients, being $91.3 \%$; and 2 patients with primary education, 8.69\%. (Graph No. 6) 


\section{Discussion:-}

During the period included in the present study, 23 patients with Type 2 Diabetes Mellitus were included, between the ages of 40 and 80 years, who came to their control on a monthly basis at the Rural Medical Unit Santa Cruz, Hecelchakán and who performed the chemical determination of creatinine in blood.

In this study, 5 cases with CRF were detected, corresponding to $21.73 \%$ (5/23), being within the parameter mentioned in the literature, in which it is mentioned that $20-40 \%$ of patients with diabetes mellitus develop diabetic nephropathy, in other articles a percentage of $10-20 \%$ is mentioned.

In the majority of patients, $43.47 \%$ (10 cases) was found in stage 1 of kidney disease classification; following in order of frequency stage 2 with $34.78 \%$ and stage 3 with $21.73 \%$; in comparison with the statistics presented in the literature, mentioning $6 \%$ of patients with chronic kidney injury in stages 1 and 2 and $4.5 \%$ of the population in stages 3 and 4; However, this discrepancy may be due to the fact that the study covers a very small population and that 15 diabetic patients were discarded, which could well increase the percentage of patients in stages 1 and 2 and decrease that of those in stage 3 and 4.

A higher prevalence of type II DM was found among females, with 18 diabetic patients against only 5 male diabetic patients. This tendency of predominance of DM type 11 is the same as that mentioned in other bibliographies. However, in this study we can see that of the total of 23 patients, the 5 who developed renal failure with GFR values $<60 \mathrm{ml} / \mathrm{min} / 1.73 \mathrm{~m} 2,100 \%$ were in the female gender, while in the male no case was detected, it is in this aspect where this study differs from others in which it has been found more predisposition in males to develop kidney disease.

\section{Conclusions:-}

In the study conducted in the Rural Medical Unit of the community of Santa Cruz, Hecelchakán, during the period from August 2017 to July 2018, 42 patients with type II DM were reported, of which 23 met the inclusion criteria. The stage classification of renal failure was performed to assess how many have developed chronic renal failure, finding that $43.47 \%$ are in stage 1 with 10 cases. In stage 2, 8 cases were found with $34.78 \%$. In stage 3 it was $21.73 \%$ reporting 5 cases. No case was classified within stages 4 and 5 .

It was determi

ned that the patients who developed CRF had an evolution time of type II DM that ranges from 6 to 10 years.

The age group where the existence of renal failure predominated was that of 60-69 years, with $80 \%$ of those affected in this age group.

The genus that presented more chronic renal failure, with a decrease in GFR $<60 \mathrm{ml} / \mathrm{min}$, was the female sex with $100 \%$ of cases.

The predominant marital status among patients with DM2, including those with CRF, was that of married (a) with $78.26 \%$.

The level of education that predominated was illiteracy, representing $91.30 \%$ among patients and $100 \%$ in those who developed CRI.

Graph No 1:- Classification according to the K / DOQI 2002 guidelines of the National Kidney Foundation

No.of cases

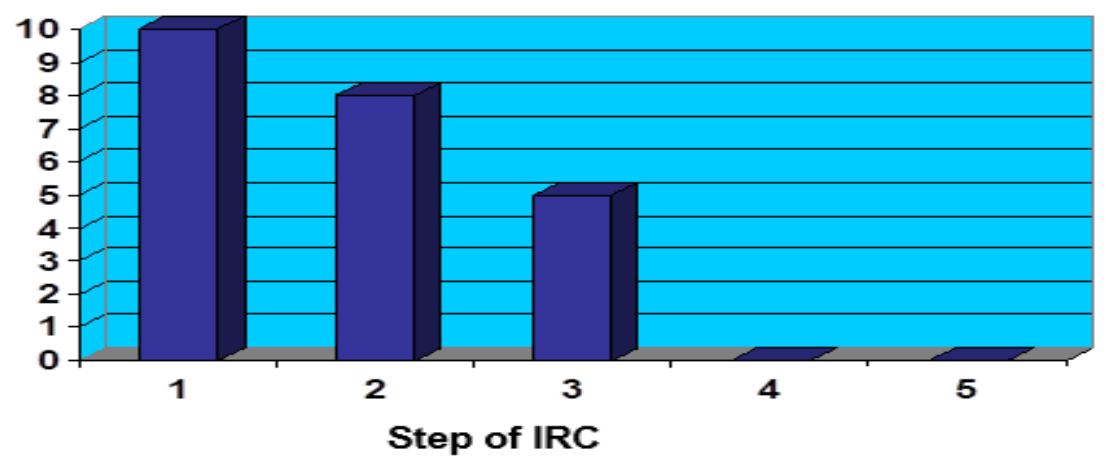


GraphNo 2:-Predominance of CKD according to the time of evolution of DM2

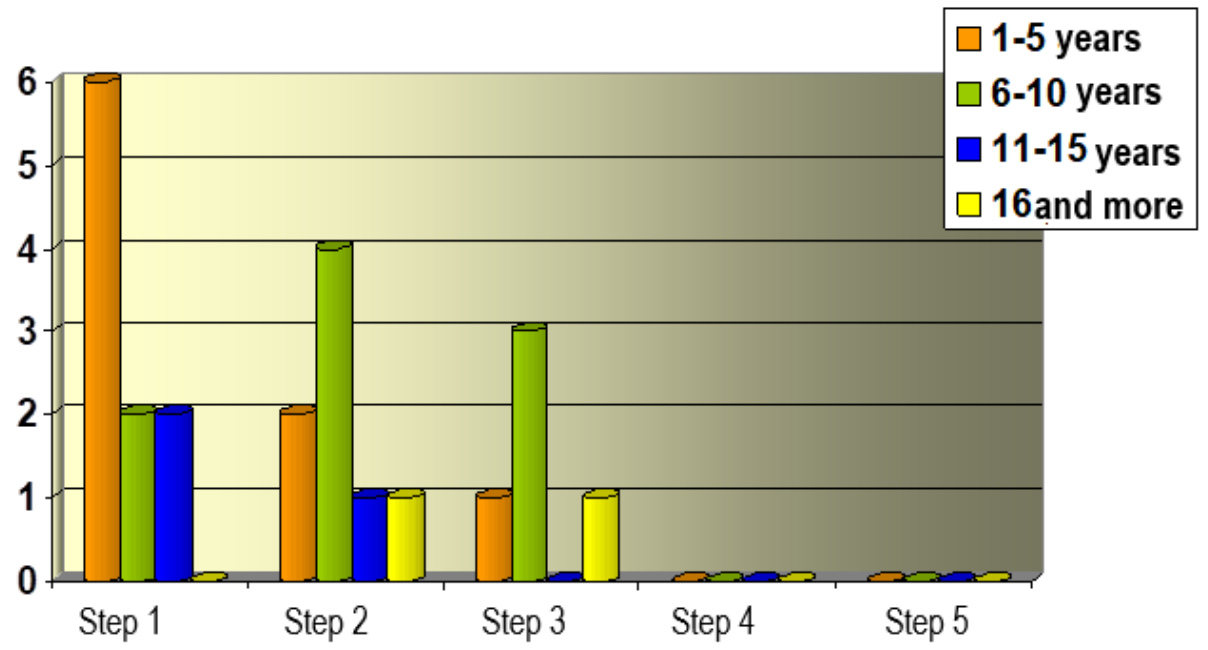

Table No 1:-Predominance of CRI cases according to the age group

\begin{tabular}{|c|c|}
\hline YEARS & CASES WITH IRC \\
\hline $40-49$ & No. OF \\
\hline $50-59$ & 0 \\
\hline $60-69$ & 4 \\
\hline $70-80$ & 1 \\
\hline
\end{tabular}

Graph No 3:-Predominance of CRI cases according to the age group

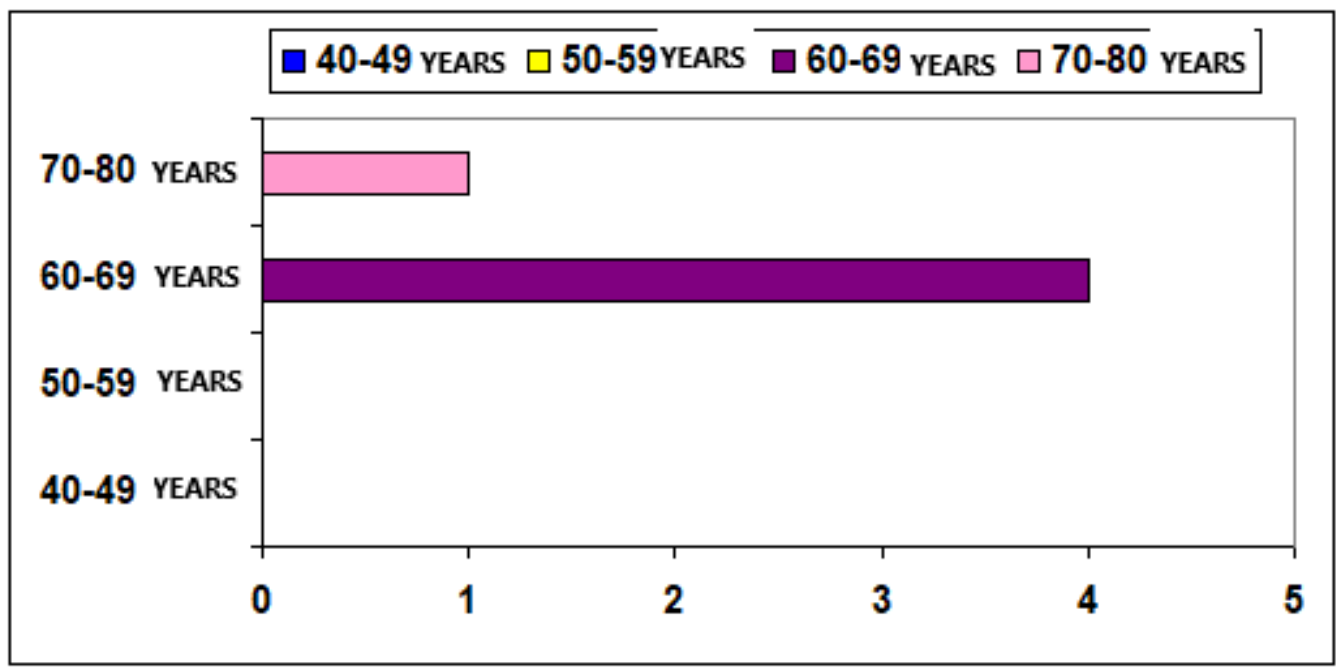


Graph No 4:-Predominance of CRI (Stages 3, 4 and 5) according to gender

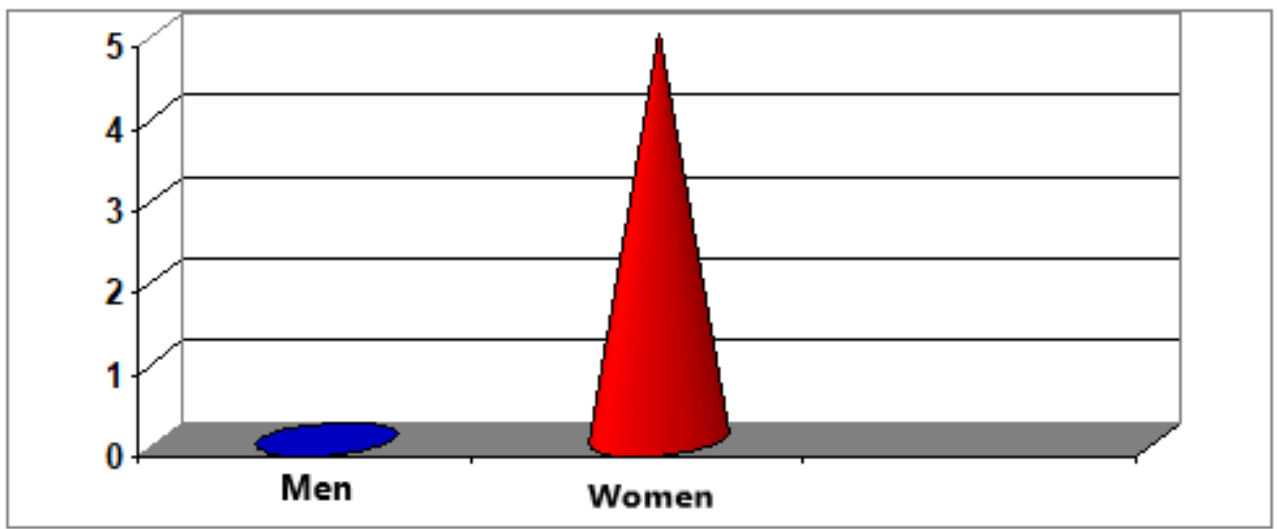

Graph No 5:-Classification of the civil status of the patients

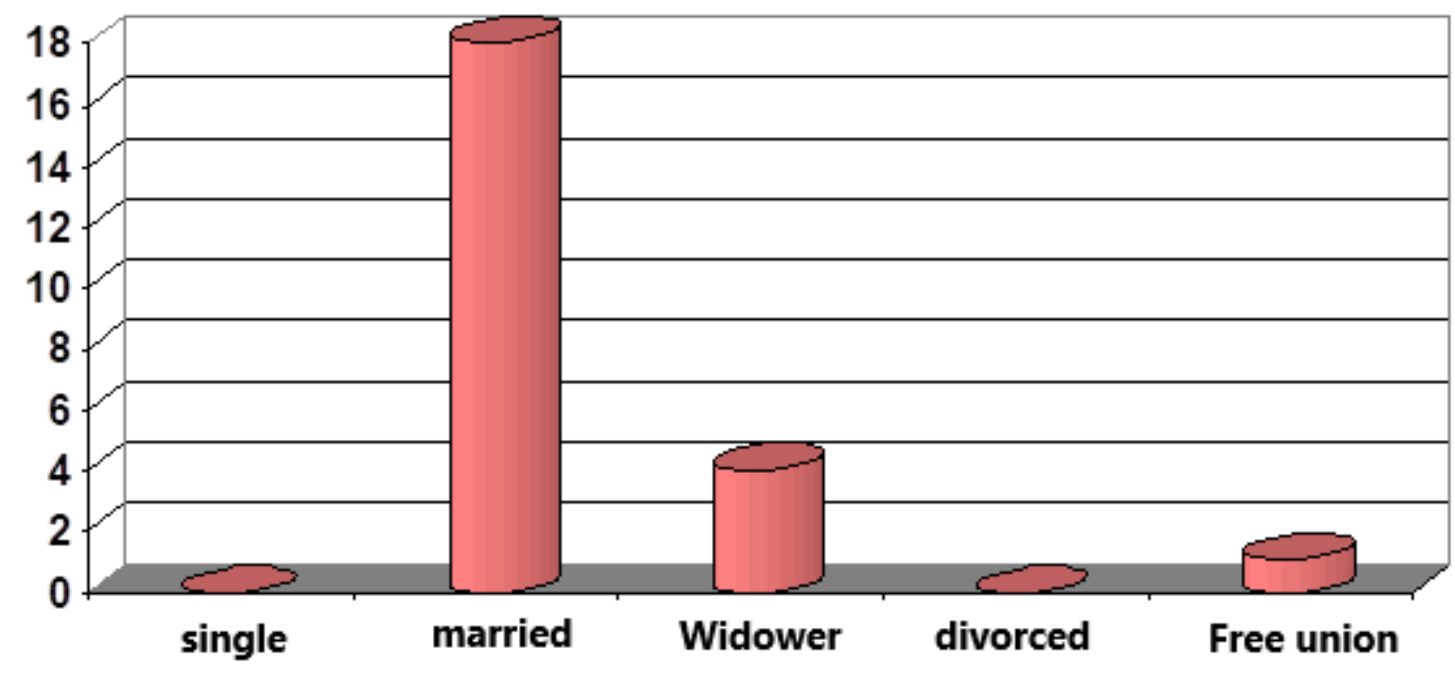

Graph No 6:-Classification of the degree of schooling of patients
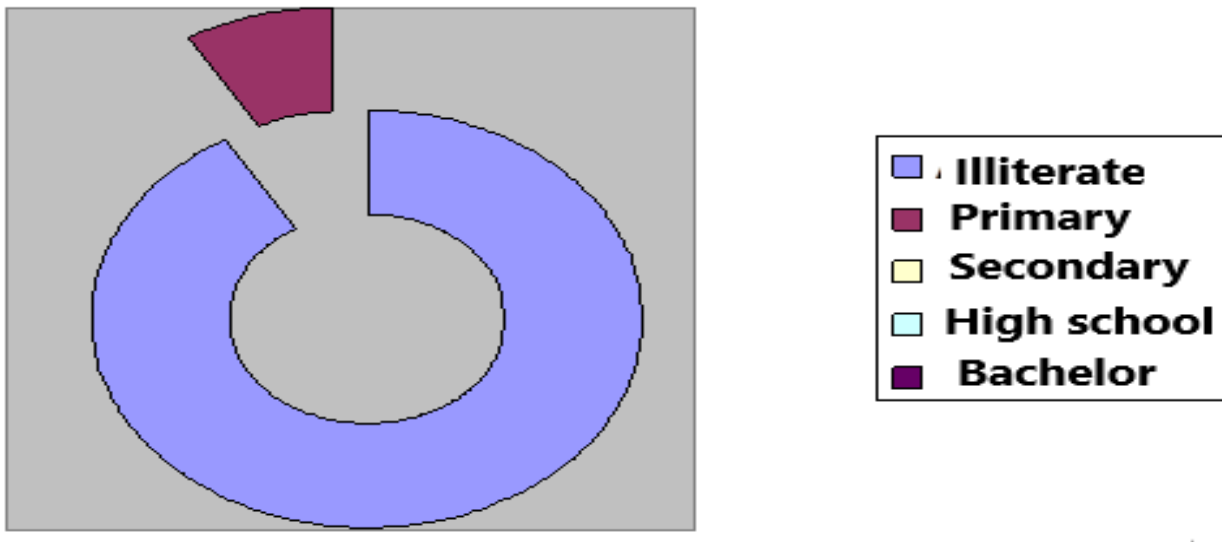


\section{Bibliográphic Refeerences:-}

1. Soriano Cabrera S. Definición y clasificación de los estadios de la enfermedad renal crónica. Prevalencia. Claves para el diagnóstico precoz. Factores de riesgo de enfermedad renal crónica. Nefrología 2004; 24 (supl 6).

2. K/DOQ1 clinical practice guidelines for chronic kidney disease, evaluation, classification and stratification. Kidney Disease Outcome Quality Initiative. Am J Kidney Dis 39 (suppl 1): S1-266. 2002

3. Harrison, Kasper, Hauser, Braunwald, et al. Principios de Medicina Interna 16a edición. Vol II Editorial Mc Graw Hill.

4. U.S. Renal Data System.USRDS 2003 Annual data Report: Atlas of end-stage renal disease in the United states. Bethesda, MD, National Institus of Health, 2003, pp 1-560.

5. Fogo AB. Progression and potential regression of glomerulosclerosis. Kidney Int 2001; 50: 804-19.

6. Tierney, McPhee, Papadakis 2005. Diagnóstico clínico y tratamiento. $40^{\mathrm{a}}$ edición. Editorial Manual Moderno.

7. Ortuño Menite J. Insuficiencia renal crónica. Medicine 2003; 8 (110): 5888-977

8. Platt R. Structural and functional adaptation en renal failure BMJ 1952; I; 1372-7.

9. Anales de cirugía cardiaca y vascular 2004; 10(1): 8-76.

10. Anales de cirugía cardiaca y vascular 2004; 10(1): 8-76. 